\title{
Growth Kinetics Study of a Bacterial Consortium Producing Biosurfactants, Constructed with Six Strains Isolated from an Oily Sludge
}

\author{
Zohra Sadouk-Hachaïchi'1,2*, Ammal Tazerouti ${ }^{1}$, Hocine Hacene ${ }^{2}$ \\ ${ }^{1}$ Laboratory of Applied Organic Chemistry, Faculty of Chemistry, University of Sciences and Technology \\ $\mathrm{H}$. Boumediène (USTHB), Algiers, Algeria \\ ${ }^{2}$ Laboratory of Microbiology, Faculty of Biological Sciences, University of Sciences and Technology \\ H. Boumediène (USTHB), Algiers, Algeria \\ Email: zz.sadouk@hotmail.com, ameltazerouti@gmail.com, h hacene@yahoo.fr
}

Received 29 January 2014; revised 2 March 2014; accepted 19 March 2014

Copyright $@ 2014$ by authors and Scientific Research Publishing Inc.

This work is licensed under the Creative Commons Attribution International License (CC BY).

http://creativecommons.org/licenses/by/4.0/

(c) (i) Open Access

\section{Abstract}

We investigated the ability of a bacterial community constructed with six strains isolated from an oily sludge, to utilize diesel oil at high concentrations. The consortium was able to grow at concentrations up to $84 \mathrm{~g}$ diesel oil/L and had produced biosurfactants during its active growth phase; these compounds, in their crude form, reduced the surface tension of distilled water from 72 $\mathrm{mN} / \mathrm{m}$ to $31 \mathrm{mN} / \mathrm{m}$, with a corresponding Critical Micelle Concentration value $\gamma_{C M C}=81 \mathrm{mg} / \mathrm{L}$. The plot of specific growth rates obtained from the growth curves versus initial concentrations was found to fit adequately the experimental data by the Andrews inhibitory model, which resulted in the following kinetic constants: $\mu_{\max }=0.535 d^{-1} \pm 0.063, K_{S}=18.68 \mathrm{~g} / \mathrm{L} \pm 3.59$ and $K_{I}=29.02 \mathrm{~g} / \mathrm{L} \pm$ 4.96, reflecting the slow biodegradation rate. At $25.2 \mathrm{~g}$ diesel oil/L, close to the optimal concentration $S^{*}=23.28 \mathrm{~g} / \mathrm{L} \pm 4.23$, the consortium metabolized diesel oil faster than each strain did individually, suggesting that the process was stimulated by a synergistic interaction between the members of the consortium.

\section{Keywords}

Andrews Model; Bacterial Consortium; Biodegradation; Biosurfactants; Diesel Oil; Kinetic Parameters

\footnotetext{
${ }^{*}$ Corresponding author.
}

How to cite this paper: Sadouk-Hachaïchi, Z., et al. (2014) Growth Kinetics Study of a Bacterial Consortium Producing Biosurfactants, Constructed with Six Strains Isolated from an Oily Sludge. Advances in Bioscience and Biotechnology, 5, 418-425. http://dx.doi.org/10.4236/abb.2014.55050 


\section{Introduction}

The specific growth rate expresses the ability of a bacterial population to increase under favorable conditions: the change depends on the population as well as time following the equation: $X(T)=X_{0} \mathrm{e}^{\mu T}$ where $X(T)$ is the bacterial abundance estimated after an incubation time $T$, and $X_{0}=X(T=0)$. The relationship between the specific growth rate $\mu=\mu(S)$ and the concentration $S$ of a substrate is regarded as an essential tool in all fields of microbiology, physiology, genetics, ecology or biotechnology [1]. Such relationship between the specific growth rate $\mu$ of a microbial pure culture and the concentration $S$ of a single substrate was formulated initially by Monod [2] as follows: $\mu=\left(\mu_{\max } S\right) /\left(K_{S}+S\right)$, where $\mu_{\max }$ is the maximum growth rate constant and $K_{s}$, defined as the substrate concentration at which $\mu=(1 / 2) \mu_{\max }$, is the saturation constant for the microorganism, substrate and cultural conditions specified. Later, Andrews [3] has proposed a mathematical model (known as Monod modified or Haldane-Andrews model) using an inhibition function to relate substrate concentration and specific growth rate as follows: $\mu=\left(\mu_{\max } S\right) /\left(K_{S}+S+\left(S^{2} / K_{I}\right)\right)$, where $K_{I}$ is an inhibition constant. The Andrews model is considered as one of the most commonly used models for describing the growth inhibition kinetics of microorganisms [4].

The abilities of certain bacteria to utilize diesel oil as growth substrate have been extensively studied using a variety of microorganisms [5]-[8].

In the present study, we used a defined bacterial community, reconstructed with six strains isolated from a residual oily sludge collected from a diesel oil storage tank, in order to model mathematically the growth of the microbial consortium using diesel oil as the carbon and energy source. The aim of the study is to define optimal conditions for the elimination of pollutants generated by the petroleum industry and to avert a possible deterioration of diesel oil quality during storage.

\section{Materials and Methods}

\subsection{Isolation and Culture Conditions}

The bacterial consortium was isolated by selective enrichment from a residual oily sludge collected from a diesel oil storage tank located in an oil refinery. Diesel oil was used at high initial concentration as the substrate to enrich the prevalent species. One gram of this sludge was added directly to a $500 \mathrm{ml}$-Erlenmeyer flask containing $100 \mathrm{ml}$ of mineral salts medium (MSM) supplemented with $0,1 \%(\mathrm{v} / \mathrm{v})$ of diesel oil (bought from a service station). The MSM used for all incubations contained (per liter of distilled water):10 g $\mathrm{KH}_{2} \mathrm{PO}_{4}, 3$ g K $\mathrm{HPO}_{4}, 2$ g $\mathrm{NH}_{4} \mathrm{NO}_{3}$ (major salts solution A) and $0.3 \mathrm{~g} \mathrm{MgSO}_{4}\left(7 \mathrm{H}_{2} \mathrm{O}\right) ; 0.1 \mathrm{~g} \mathrm{NaCl} ; 10 \mathrm{mg} \mathrm{CaCl} 2 ; 1 \mathrm{mg} \mathrm{MnCl}_{2} ; 1 \mathrm{mg}$ $\mathrm{CuCl}_{2}, 1 \mathrm{mg} \mathrm{FeSO}, 1 \mathrm{mg} \mathrm{ZnSO}_{4}$ and $0.1 \mathrm{mg} \mathrm{MoO}_{3}$ The $\mathrm{pH}$ of the solution A was adjusted to $\mathrm{pH}=7$ with $\mathrm{NaOH}$ before autoclaving $\left(120^{\circ} \mathrm{C}, 20 \mathrm{~min}\right)$. The other elements were sterilized separately $\left(120^{\circ} \mathrm{C}, 20 \mathrm{~min}\right)$ and added aseptically, after cooling at room temperature, to solution A to form MSM. Culture was incubated aerobically on a rotary platform shaker operating at 100 rotations/min (rpm) (Janke \& Kunkel, IKA-WERH, KS 500). Diesel oil was used as the substrate to enrich the prevalent species: the enrichments were transferred four times at a $10 \%(\mathrm{v} / \mathrm{v})$ inoculum into $500 \mathrm{ml}$-Erlenmeyer flask containing $90 \mathrm{ml}$ of MSM supplemented with $1 \%$ $(\mathrm{v} / \mathrm{v})$ diesel oil (=8.4 g diesel oil/L).

The enriched bacterial consortium was identified to contain six bacterial strains. The microorganisms were isolated as pure cultures by the conventional streak-plate technique and transferred to liquid cultures. A preculture was carried out in $250 \mathrm{ml}$-Erlenmeyer flask containing $50 \mathrm{ml}$ of MSM with diesel oil at the concentration 0, $25 \%(\mathrm{v} / \mathrm{v})$. The flask was incubated during 48 hours at $27^{\circ} \mathrm{C}$ under $100 \mathrm{rpm}$ rotary shaking. $8 \mathrm{ml}$ of the preculture were inoculated into $500 \mathrm{ml}$-Erlenmeyer flasks containing $100 \mathrm{ml}$ of MSM added with diesel oil at the concentration ranging from $1 \%$ to $10 \%(\mathrm{v} / \mathrm{v})$. The flasks were incubated at $27^{\circ} \mathrm{C}$ under $100 \mathrm{rpm}$ rotary shaking.

Growth was followed during the intervals between sampling by the measure of the optical density $\left(\mathrm{OD}_{600}\right)$ of culture sample diluted at $10^{-1}$, by means of the spectrophotometer MF $320 \mathrm{~N}$ DO (JOUAN S.A-FRANCE); due to the poorly soluble nature of diesel oil in water, the measures were achieved as described in [9]. All experiments were performed in duplicate. Activity assays were done in duplicate and plotted as mean values.

\subsection{Follow-Up of the Cultures}

\section{- Calibration curve}

As cell concentrations were estimated by measuring the optical density at $600 \mathrm{~nm}\left(O D_{600}\right)$ of the bacterial 
culture samples diluted at $10^{-1}$, a correlation curve was made to relate $O D_{600}$ of the bacterial culture with $8.4 \mathrm{~g}$ diesel oil/L, to colony forming units (CFU). The number of viable cells in one milliliter of each bacterial culture sample was estimated using the standard plate count method, and plotted versus the $\mathrm{OD}_{600}$ of the original sample: resulting the fitted equation:

$\mathrm{CFU} / \mathrm{ml}=\left(16.08+268.81 \cdot O D_{600}\right) 10^{8}$, which allowed for direct conversion of $O D_{600}$ measurements to viable cells concentration: $\mathbf{0 . 1} O D_{600}$ unit of the culture medium represents $\mathbf{4 3} \times \mathbf{1 0}^{\mathbf{8}} \mathbf{U F C} / \mathbf{m l}$.

\section{- Recovery of crude extract}

The resulting product was extracted from the cell-free culture supernatant as described in [10].

\section{- Growth rate calculation}

It is well known that the bacterial concentration is proportional to the optical density $\left(O D_{600}\right)$ of the culture medium sufficiently diluted (Beer-Lambert law). As the bacterial abundance is expressed as the $O D_{600}$ of bacterial culture samples diluted at $10^{-1}$, measured in a semi-logarithmic scale, to determine the exponential growth rate $\mu=\mu(S)$ for each initial concentration $S$ of diesel oil tested, we have to consider the linear part of a plot of $Y(T)=\log \left(O D_{600}(T) / 10\right)$ versus incubation time, where $O D_{600}(T)=O D_{0} \exp (\mu T)$ and

$O D_{0}=O D_{600}(T=0)$.

Using the plotting program "fit linear" of the software "Origin 5.0" (Microcal software Inc.) we determine $\mu=B /(\log e)=2.3026 B$, from the fitted equation: $Y(T)=A+B T=\log \left(O D_{0} / 10\right)+(\mu \log e) T$.

\section{- Surface tension and emulsifying activity measurements}

The emulsifying activity in the culture medium was estimated as described in Cooper and Goldenberg [11]. The surface tension of the crude extract was measured with a tensiometer CSC-DUNOUY 40902 using the ring technique: the $\mathrm{E}_{24}$ emulsion index is considered as most suitable for the measure of biosurfactants emulsifying activity [12].

\section{- Nucleotide sequence accession numbers}

The 16S rRNA gene sequences of Pseudomonas citronellolis strain KHA and Serratia marscecens LHA have been deposited in the GenBank database under accession numbers EF 593111 and EF 616470, respectively.

\section{Results and Discussion}

Diesel oil is a complex mixture of hydrocarbons which consists mainly of linear and branched alkanes that are highly variable in susceptibility to biodegradation. We were interested in investigating the concentration dependency of diesel oil metabolism rates for the six bacterial strains cultivated as pure culture, then as mixed bacterial culture.

\subsection{Growth Kinetics of the Six Strains Cultivated as Pure Culture with Diesel Oil (3\% v/v)}

The results are shown in Figure 1 and further details are given in Table 1.

Figure 1 shows that all isolates were able to grow on diesel oil, and have produced bioemulsifier compounds during the active growth phase: Pseudomonas citronellolis has exhibited the best emulsifying activity, followed by the strains AM and FFH.

Compared with others members of the consortium, the strains KHA and AM express the best biological activity against the diesel oil ( $\mu=0.177 \mathrm{~d}^{-1}$ and $\mu=00174 \mathrm{~d}^{-1}$, respectively). The active growth phase of the strain KHA stops after 117 hours of incubation, while that of the other strains ceases only after 235 hours, and up to 307 hours for the strain MH: this suggests that strain Pseudomonas. citronellolis KHA has a specialized niche in the hydrocarbons degradation by the consortium.

It should be noted that the strain KHA starts its active growth phase after a very short lag phase, which means that the cells have synthesized all the enzymes that they needed for growth, in proper amount, during the preculture at $0,1 \%(\mathrm{v} / \mathrm{v})$ diesel oil. In contrast, the others isolates needed a lag phase much longer, especially $\mathrm{MH}$ and NE1.

\subsection{Growth Kinetics of the Bacterial Community}

The results are shown in Figures 2 and 3, and further details are given in Table 2.

The bacterial community consists of the following isolates: Pseudomonas citronellolis KHA, Serratia mar- 
Table 1. Specific growth rates calculated for the members of the bacterial consortium growing with $25.2 \mathrm{~g}$ diesel oil/L.

\begin{tabular}{ccccccc}
\hline Bacterial strain & KHA & AM & LHA & FFH & MH & NE1 \\
\hline $\boldsymbol{\mu}$ : Specific growth rate in $\mathrm{d}^{-1}$, (d = day) & $0.177 \pm 0.014$ & $0.174 \pm 0.009$ & $0.146 \pm 0.003$ & $0.110 \pm 0.007$ & $0.077 \pm 0.004$ & $0.044 \pm 0.006$ \\
Standard Deviation of the fit & 0.016 & 0.016 & 0.005 & 0.027 & 0.014 & 0.019 \\
Maximum $_{24}$ emulsion index (\%) & 75 & 42 & 36 & 45 & 11 & 10 \\
\hline
\end{tabular}

KHA: Pseudomonas citronellolis; LHA: Serratia marcescens; FFH: Micrococcus luteus; MH: Pseudomonas spp. AM and NE1: Gram-negative, rodshaped and motile bacteria.

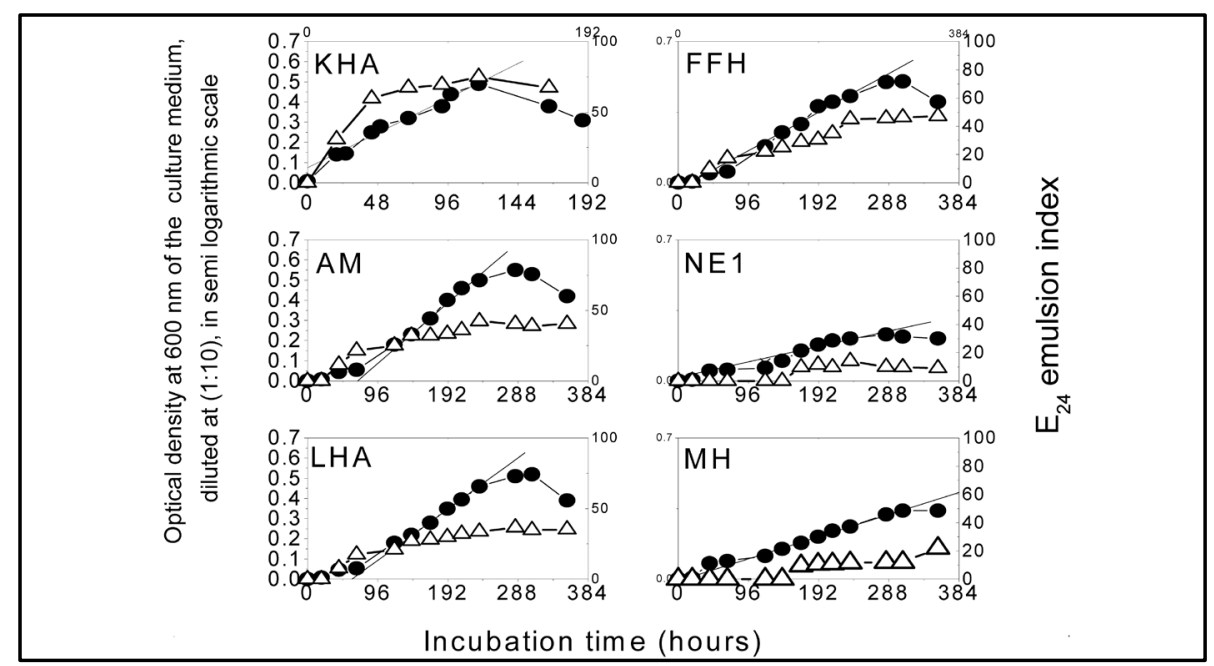

KHA: Pseudomonas citronellolis; FFH: Micrococcus luteus; LHA: Serratia marcescens; MH: Pseudomonas spp. AM and NE1: Gram-negative, rod-shaped and motile bacteria.

Figure 1. Growth curves $(\bullet)$ and emulsifier production measured as $E_{24}$ emultion index $(\Delta)$ expresses by each member of the bacterial consortium cultivated with $25.2 \mathrm{~g}$ diesel oil/L.

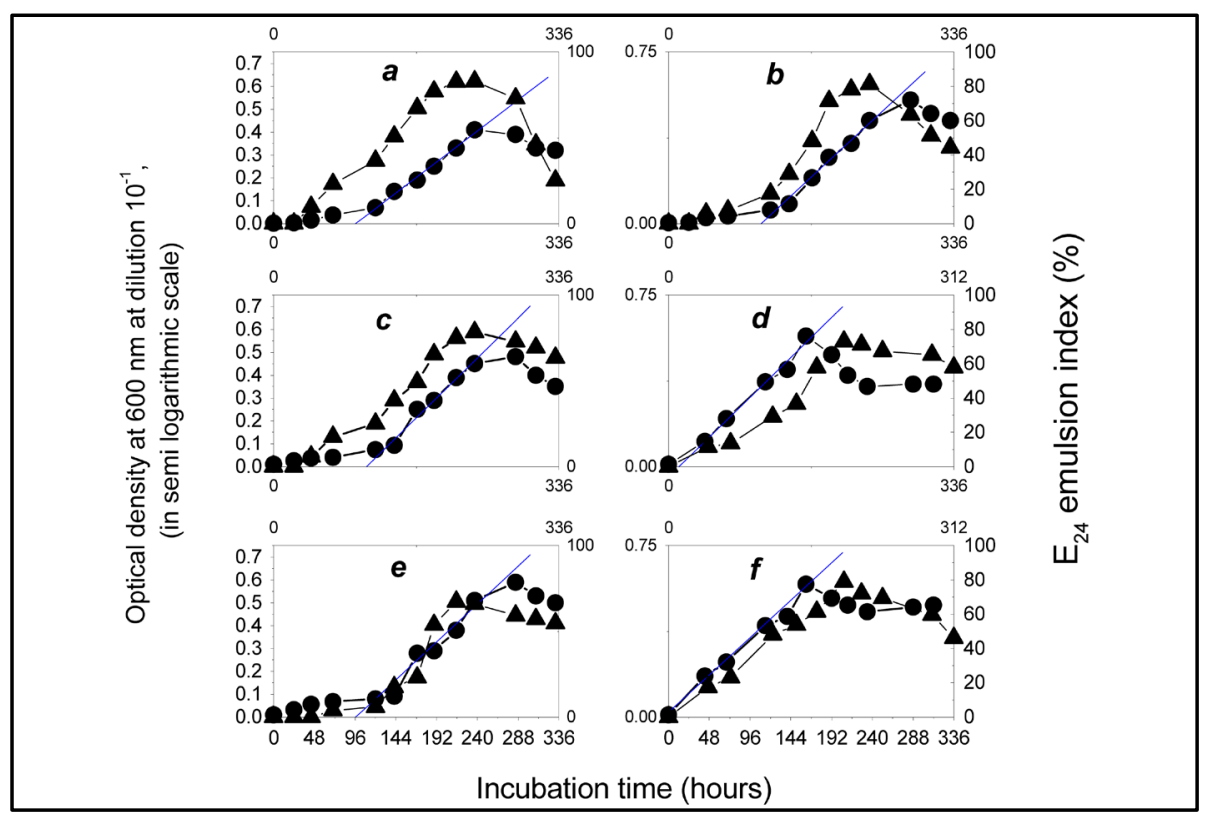

$\boldsymbol{a}: 1 \%$; $\boldsymbol{b}: 2 \% ; \boldsymbol{c}: 3 \% ; \boldsymbol{d}: 4 \%$; $: 5 \% ; \boldsymbol{f}: 6 \%(\mathrm{v} / \mathrm{v}) . \bullet: \mathrm{OD}_{600}$ of the bacterial culture medium diluted at $10^{-1} . \mathbf{\Lambda}$ : Emulsification activity (measured as $\mathrm{E}_{24}$ emulsion index of the bacterial culture medium).

Figure 2. Growth curves of the bacterial community using diesel oil as the sole carbon and energy source, at the initial concentration. 
Table 2. Specific growth rates corresponding to bacterial community calculated for the initial concentrations of diesel oil ranging between $1 \%-10 \%(\mathrm{v} / \mathrm{v})$.

\begin{tabular}{cccccccccccc}
\hline Diesel oil concentration $(\mathrm{g} / \mathrm{L})$ & 8.4 & 16.8 & 25.2 & 33.6 & 42 & 50.4 & 58.8 & 67.2 & 75.6 & 84 \\
Specific growth rate $\left(\mathrm{d}^{-1}\right)$ & 0.1558 & 0.1945 & 0.2012 & 0.2006 & 0.1884 & 0.1768 & 0.163 & 0.147 & 0.1354 & 0.1266 \\
Error $\left(\mathrm{d}^{-1}\right)$ & 0.0073 & 0.0101 & 0.0191 & 0.0153 & 0.0095 & 0.0167 & 0.0102 & 0.0244 & 0.0209 & 0.0175 \\
Standard deviation of the fit & 0.013 & 0.0136 & 0.026 & 0.027 & 0.015 & 0.03 & 0.014 & 0.033 & 0.029 & 0.024 \\
Maximum $\mathrm{E}_{24}$ emulsion index \% & 82.7 & 81.2 & 78.3 & 73 & 67.3 & - & 64.3 & 55.7 & 44.8 & 42.6 \\
\hline
\end{tabular}

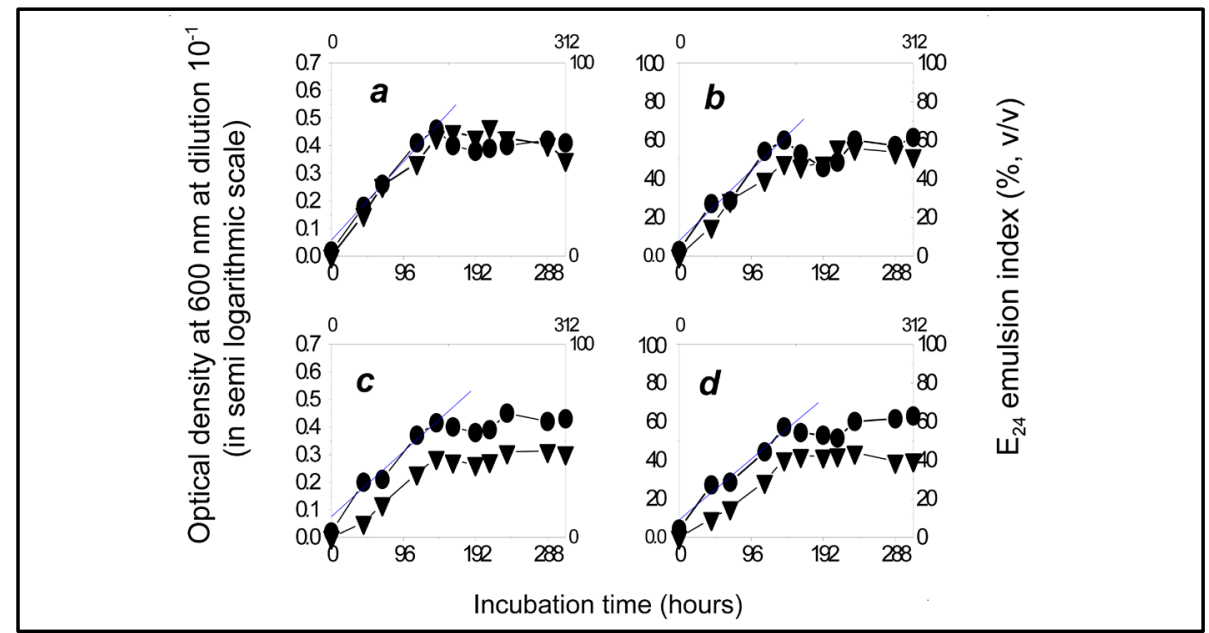

$\boldsymbol{a}: 7 \% ; \boldsymbol{b}: 8 \% ; \boldsymbol{c}: 9 \% ; \boldsymbol{d}: 10 \%(\mathrm{v} / \mathrm{v}) . \bullet: \mathrm{OD}_{600}$ of the bacterial culture medium diluted at $10^{-1}$. $\boldsymbol{\Lambda}$ : Emulsification activity (measured as $\mathrm{E}_{24}$ emulsion index of the bacterial culture medium).

Figure 3. Growth curves of the bacterial community using diesel oil as the sole carbon and energy source, at the initial concentration.

cescens LHA, Micrococcus luteus FFH, Pseudomonas spp. MH and two Gram-negative, rod-shaped and motile bacteria AM and NE1.

Figures 2 and 3 show that the proliferation of the microbial population, which is the direct result of the substrate uptake by the microorganisms [13], was accompanied by the emulsification of the culture medium as demonstrated by the increase of the $\mathrm{E}_{24}$ emulsion index during the microbial active growth phase, at all substrate concentrations tested: this suggests that the microorganisms assimilated diesel oil according to the well known mode of emulsifier-mediated transfer t [14].

Maximum emulsifying activity $\left(E_{24}=82 \%\right)$ was obtained after 237 hours of incubation, when the consortium grows with $8.4 \mathrm{~g}$ diesel oil/L in the culture medium. Table 2 shows that the index decreases gradually when the substrate concentration in the culture medium increases from $1 \%(\mathrm{v} / \mathrm{v})$ to $10 \%(\mathrm{v} / \mathrm{v})$, what indicates that the substrate initial concentration induces inhibiting effects on the biosynthesis of the emulsifying compounds by the consortium.

It should be noted that, if a single strain typically is capable of using a limited number of the compounds found in the hydrocarbons, a consortium composed of different bacteria species is usually involved in the degradation of theses complexes mixtures [15]. It is well known, in addition, that microbial communities may respond to varying supply of organic compounds either by physiological adaptation or by changes in the community composition.

\subsection{Estimation of Kinetic Parameters and Modelling}

Data representing the linear fraction of the consortium growth curves corresponding to the active growth phase were used to calculate specific growth rates $\mu(S)$ for each initial concentration $\boldsymbol{S}$ of diesel oil tested. Table 2 shows the results obtained for the bacterial consortium 
These results were then plotted versus initial concentration of diesel oil for examination of the shape of the curves developed. Figure 4 shows clearly that the bacterial community has exhibited an increasingly inhibitory response to the initial concentration of diesel oil, in accordance with the Andrews inhibitory model defined by the equation: $\mu(S)=\mu_{\max } \frac{S}{K_{S}+S+\left(S^{2} / K_{I}\right)}$, where $K_{S}$ is the affinity constant and $K_{I}$ is the inhibition constant.

The representative curve of the function $\mu(S)$ reached a peak value at the initial concentration $S^{*}$ solution of the equation: $\mathrm{d} \mu(S) / \mathrm{d} S=0=0$, so that: $S^{*}=\sqrt{K_{S} K_{I}}$, with the error:

$\Delta S^{*}=\left(K_{S} \Delta K_{I}+K_{I} \Delta K_{S}\right) /\left(2 \sqrt{K_{S} K_{I}}\right)$.

The calculated kinetic parameters from the Andrews equation for the bacterial consortium are summarized in Table 3.

We can conclude that the consortium expressed a weak affinity for diesel oil and, at higher concentrations, marked inhibition effects were observed, characterized by the decrease of the specific growth rates.

\subsection{Biosurfactants Production by the Bacterial Consortium}

Surfactants are amphiphilic compounds which reduce surface and interfacial tensions by accumulating at the interface of immiscible fluids. Most of these surfactants are petroleum based and are chemically synthesized. However the leading trend towards using environmental friendly technologies has enhanced the search for compounds of bacterial origin that act as emulsifiers and surface-active agents and having the abilities to reduce significantly surface tension of aqueous media: such microbial compounds are classified as "biosurfactants". Biosurfactants are becoming important biotechnological products for industrial applications due to their environmental friendly nature, low toxicity, biodegradability and effectiveness at a wide range of $\mathrm{pH}$ and temperature values.

Most biosurfactants, like synthetic surfactants, exhibit physicochemical properties such detergency, emulsification, de-emulsification, foaming and wetting. Interest in their potential applications by various industries has significantly increased recently.

\subsection{Calculation of Critical Micelle Concentration (CMC) of the Crude Product}

The CMC is defined as the concentration of a surfactant at which the surface-active ions or molecules in solution associate to form larger units, called micelles. The CMC corresponds to the point beyond which the concentration of single molecules of surfactant remains relatively constant. The CMC is commonly used to measure the efficiency of surface-active agents.

To obtain a measure of the CMC of our crude extract, the product was diluted in a serial dilution in distilled water, and the surface tension was measured for each dilution. The plots of the logarithmic crude extract concentration versus the surface tension were made: the results are shown in Figure 5.

Using the program "linear fit" of the software ORIGIN 5.0, linear least-squares analyses of both the points before and the points after the break show that the minimal surface tension reaches at the point

$(X=1.91 ; Y=30.7)$ which corresponds to the intersection of the fitted lines $Y=44.93-7.46 X$ and $Y=31.32-0.33 X$ : resulting the CMC of the crude extract: $\gamma_{C M C}=81 \mathrm{mg} / \mathrm{L}$.

Table 3. Kinetics parameters determined from the inhibitory model for the microbial consortium growing with diesel oil as the carbon and energy source, from 8.4 to $84 \mathrm{~g}$ diesel oil/L.

\begin{tabular}{|c|c|}
\hline Kinetic parameters & Bacterial consortium \\
\hline$\mu_{\max }\left(d^{-1} ; d=d a y\right)$ & $0.535 \pm 0.063$ \\
\hline$K_{s},(\mathrm{~g} / \mathrm{L})$ & $18.68 \pm 3.594$ \\
\hline$K_{I},(\mathrm{~g} / \mathrm{L})$ & $29.017 \pm 4.963$ \\
\hline$S^{*}=\sqrt{K_{S} K_{I}},(\mathrm{~g} / \mathrm{L}) \quad($ Optimal concentration $)$ & $23.28 \pm 4.231$ or $2.77 \%(v / v) \pm 0.5$ \\
\hline
\end{tabular}




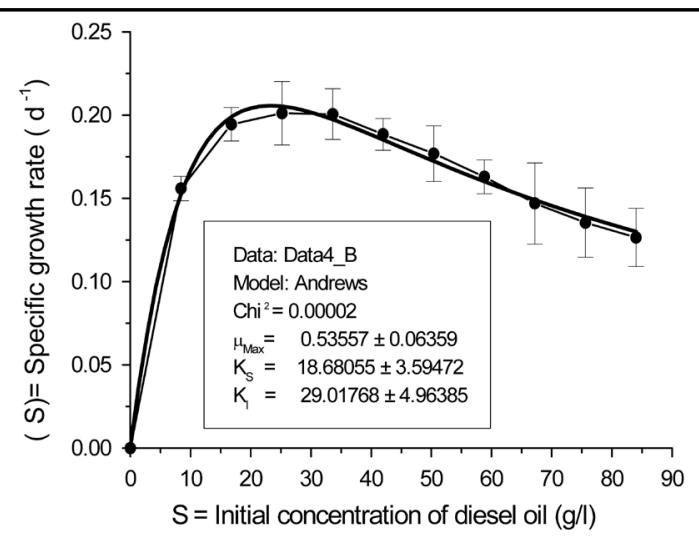

Figure 4. Specific growth rates $\mu(S)$ versus substrate initial concentration for the bacterial community growing with diesel oil as the carbon and energy source at the initial concentrations varying from $8.4 \mathrm{~g} / \mathrm{L}$ to $84 \mathrm{~g} / \mathrm{L}$.

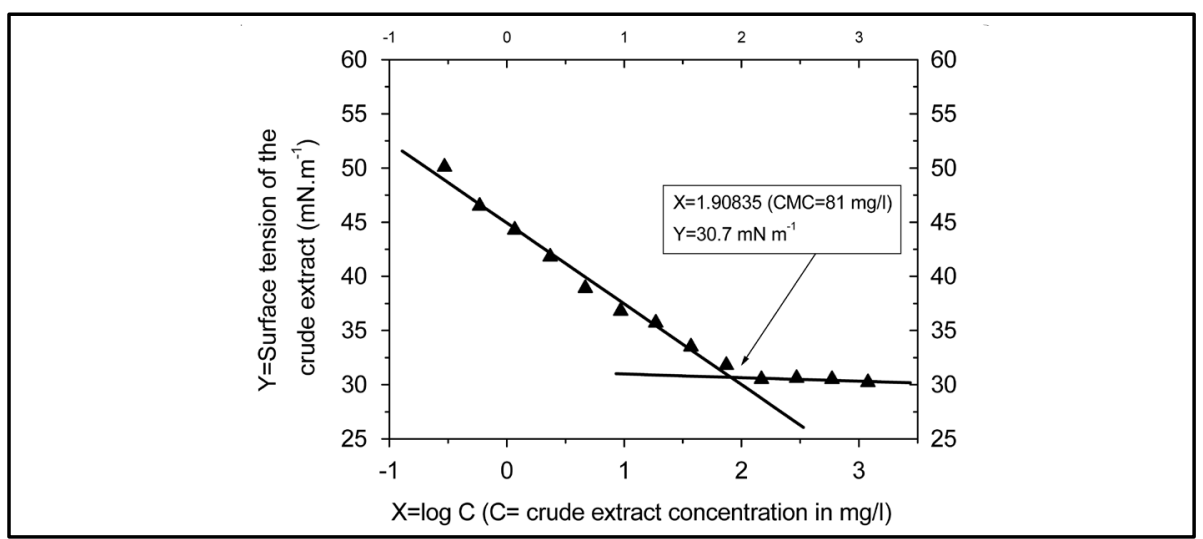

Figure 5. Determination of the CMC value of the crude extract from the surface tension vs. concentration plot. The black up triangles spots represent the experimental data, the lines are the fitting linear curves. CMC is determined as the intersection point of the two lines.

Since the crude extract exhibited a high emulsifying activity and decreases the surface tension of distilled water from 72 to $30.7 \mathrm{mN} / \mathrm{m}$, it has the characteristics of a biosurfactant compounds.

Hence, the biosurfactants produced by the consortium exhibit interesting surface active properties that can be useful in the petroleum industries, such as cleaning oils tanks, enhanced oil recovery procedures (MEOR) or bioremediation of sites polluted by hydrocarbons.

\section{Conclusion}

This study shows that the degradation of (some compounds of) diesel oil can be performed individually by each isolate composing the consortium, especially by the strain KHA, but the bacterial community possesses a better potential for the degradation of a much broader set of diesel oil compounds, suggesting that the process is a result of interspecies interactions. Hence, the bacterial consortium possesses a substantial potential for the cleaning up of soils contaminated with hydrocarbons resulting from industrial activities related to refining, transportation and/or disposal of petroleum product. In addition, the high quality of biosurfactant compounds produced by this culture allows their use in a crude form for biotechnological applications without the need for product concentration or purification.

\section{Acknowledgements}

We tank Professor Wafa ACHOUAK (LEMIR, UMR 6191 CNRS-CEA-Univ. Aix-Marseille II, CEA Cada- 
rache-France) for the nucleotide sequence determination of the strains KHA and LHA.

\section{References}

[1] Kovarova-Kovar, K. and Egli, T. (1998) Growth Kinetics of Suspended Microbial Cells: From Single-Substrate-Controlled Growth to Mixed-Substrate Kinetics. Microbiology and Molecular Biology Reviews, 62, 646-666.

[2] Monod, J. (1949) The Growth of Bacterial Cultures. Annual Review of Microbiology, 3, 371-394. http://dx.doi.org/10.1146/annurev.mi.03.100149.002103

[3] Andrews, J.F. (1968) A Mathematical Model for the Continuous Culture of Microorganisms Utilizing Inhibitory Substrates. Biotechnology and Bioengineering, 10, 707-723. http://dx.doi.org/10.1002/bit.260100602

[4] Hao, O.J., Kim, M.H., Seagre, E.A. and Kim, H. (2002) Kinetics of Phenol and Chlorophenol Utilization by Acinetobacter species. Chemosphere, 46, 797-807. http://dx.doi.org/10.1016/S0045-6535(01)00182-5

[5] Young, C.-C., Lin, T.-C., Yeh, M.-S., Shen, F.-T. and Chang, J.-S. (2005) Identification and Kinetic Characteristics of An Indigenous Diesel-Degrading Gordonia alkanivorans Strain. World Journal of Microbiology and Biotechnology, 21, 1409-1414. http://dx.doi.org/10.1007/s11274-005-5742-7

[6] Hawle-Ambrosch, E., Riepe, W., Dornmavr-Pfaffenhuemer, M., Radax, C., Holzinger, A. and Stan-Lotter, H. (2007) Biodegradation of Fuel Oil Hydrocarbons by a Mixed Bacterial Consortium in Sandy and Loamy Soils. Biotechnology Journal, 2, 1564-1568. http://dx.doi.org/10.1002/biot.200700082

[7] Sadouk, Z., Tazerouti, A. and Hacene H (2009) Biodegradation of Diesel Oil and Production of Fatty Acid Esters by a Newly Isolated Pseudomonas citronellolis KHA. World Journal of Microbiology and Biotechnology, 25, 65-70. http://dx.doi.org/10.1007/s11274-008-9863-7

[8] Kaczorek, E., Jesionowski, T. and Giec, A. (2012) Cell Surface Properties of Pseudomonas stutzeri in the Process of Diesel Oil Biodegradation. Biotechnology Letters, 34, 857-862. http://dx.doi.org/10.1007/s10529-011-0835-X

[9] Whyte, L.G., Slagman, S.J, Pietrantonio, F., Bourbonnière, L., Koval, S.F., Lawrence, J.R.., Inniss, W.E. and Greer, C.W. (1999) Physiological Adaptations Involved in Alkane Assimilation at a Low Temperature by Rhodococcus sp. Strain Q15. Applied and Environmental Microbiology, 65, 2961-2968.

[10] Rapp, P. and Gabriel-Jürgens, L.H.E. (2003) Degradation of Alkanes and Highly Chlorinated Benzenes, and Production of Biosurfactants, by a Psychrophilic Rhodococcus sp. and Genetic Characterization of Its Chlorobenzene Dioxygenase. Microbiology, 149, 2879-2890. http://dx.doi.org/10.1099/mic.0.26188-0

[11] Cooper, D.G. and Goldenberg, B.G. (1987) Surface-Active Agents from Two Bacillus Species. Applied and Environmental Microbiology, 53, 224-229.

[12] Desaï, J.D. and Banat, I.M. (1997) Microbial Production of Surfactants and Their Commercial Potential. Microbiology and Molecular Biology Reviews, 61, 47-64.

[13] Button, D.K. (1985) Kinetics of Nutrient-Limited Transport and Microbial Growth. Microbiological Reviews, 49, 270297.

[14] Bouchez-Naïtali, M., Rakatozafy, H., Marchal, R., Leveau, J.Y. and Vandecasteele, J.P. (1999) Diversity of Bacterial Strains Degrading Hexadecane in Relation to the Mode of Substrate Uptake. Journal of Applied Microbiology, 86, 421-8. http://dx.doi.org/10.1046/j.1365-2672.1999.00678.x

[15] Röling, W.F.M., Milner, M.G., Jones, D.M., Lee, K., Daniel, F., Swannell, R.J.P. and Head, I.M. (2002) Robust Hydrocarbon Degradation and Dynamics of Bacterial Communities during Nutrient-Enhanced Oil Spill Bioremediation. Applied and Environmental Microbiology, 68, 5537-5548. Environmental Microbiology, 53, 224-229. 